\title{
Severe respiratory depression precipitated by unrecognized gastric perforation during endoscopic submucosal dissection under deep sedation - A case report -
}

\section{Go-Eun Kim, Sang Hyun Lee, In Sun Chung, Eunji Lee, Hyun Su Shin, and Ji-won Choi}

Department of Anesthesiology and Pain Medicine, Samsung Medical Center, Sungkyunkwan University School of Medicine, Seoul, Korea
Received May 12, 2017

Revised July 5, 2017

Accepted July 14, 2017

\author{
Corresponding author \\ Ji-won Choi, M.D. \\ Department of Anesthesiology and \\ Pain Medicine, Samsung Medical \\ Center, Sungkyunkwan University \\ School of Medicine, 81, Irwon-ro, \\ Gangnam-gu, Seoul 06351, Korea \\ Tel: 82-2-3410-7455 \\ Fax: 82-2-3410-0368 \\ E-mail: jiwon0715.choi@samsung.com
}

Endoscopic submucosal dissection (ESD) is widely performed these days as the standard procedure for the treatment of early gastric cancer. During ESD, insertion and rotation of the scope, air insufflation, incision and hemostasis may provoke pain, which commonly requires either general anesthesia or moderate to deep sedation. Deep sedation precludes the need for general anesthesia, and can help endoscopists speed up the procedure compared to light sedation. But, there are risks of respiratory complication. We report a case of respiratory compromise caused by pneumoperitoneum from unrecognized gastric perforation during ESD under deep sedation.

Key Words: Deep sedation, Endoscopic submucosal dissection, Pneumoperitoneum, Respiratory depression.
Endoscopic submucosal dissection (ESD) has become the standard procedure for treatment of early gastric cancer [1]. Few studies have addressed anesthesia or sedation methods during ESD [2-5]. In Yurtlu et al. [2] general anesthesia was compared with propofol based sedation, and in Park et al. [3] intermittent and continuous sedation methods were compared. When sedation is used during ESD, it is usually moderate to deep sedation because of the long procedure time and pain caused by incision, dissection, hemostasis, air insufflation and rotation of the scope $[6,7]$. However, there are concerns about respiratory complications, such as respiratory depression and aspiration pneumonia when deep sedation is used in ESD [6]. Recently, Yoo et al. [6] reported that sedation targeted to light sedation could be an alternative to moderate sedation with a score of 2 or 3 from Modified Observer's Assessment of Alertness/Sedation (Table 1). Light sedation during ESD permits some movement and cooperation from patients. However, this may hinder endoscopists from performing the procedure efficiently and could prolong the procedural time. Therefore, moderate to deep sedation is the generally agreed level of sedation for better procedural condition, which allows the endoscopist to perform ESD with

Table 1. Modified Observer's Assessment Sedation Score Modified observer's assessment of alertness/sedation scale

5 Responds readily to name spoken in normal tone

$4 \quad$ Lethargic response to name spoken in normal tone

3 Responds only after name is called loudly and/or repeatedly

2 Responds only after mild prodding or shaking

1 Responds only after painful trapezius squeeze

$0 \quad$ No response after painful trapezium squeeze

This is an Open Access article distributed under the terms of the Creative Commons Attribution Non-Commercial License (http://creativecommons.org/licenses/by-nc/4.0) which permits unrestricted non-commercial use, distribution, and reproduction in any medium, provided the original work is properly cited. 
ease and shorten the procedure time [7]. We provide deep sedation upon the request of the attending endoscopist. In this paper, we report a case and the management of periprocedural severe respiratory depression precipitated by unrecognized gastric perforation during ESD under propofol and remifentanil based deep sedation.

\section{CASE REPORT}

A 54-year-old man (height, $174.9 \mathrm{~cm}$; weight, $65.3 \mathrm{~kg}$ ) was admitted to our hospital to treat a gastric lesion found incidentally during health examination two month previously. Esophagogastroduodenoscopy (EGD) revealed a $2 \mathrm{~cm}$, flat, erythematous geographic lesion mainly located at the anterior wall of the proximal antrum. The patient had no other underlying disease, no history of obstructive sleep apnea and no history of snoring. The laboratory findings were unremarkable. We decided to perform ESD under sedation using continuous infusion of propofol and remifentanil according to our hospital's ESD sedation regimen.

Premedication was with an antifoaming agent, simethicone, administered orally at $80 \mathrm{mg} 1$ hour before the procedure, and with the anti-muscarinic agent cimetropium $5 \mathrm{mg}$ administered intravenously (IV) just before the procedure. In the ESD procedural suite, the patient's electrocardiogram (ECG), noninvasive blood pressure and peripheral oxygen saturation $\left(\mathrm{SpO}_{2}\right)$ were monitored. Before sedation, the blood pressure was $107 / 69 \mathrm{mmHg}$, pulse rate was 58 beats/min and oxygen saturation level $\left(\mathrm{SpO}_{2}\right)$ was $97 \%$. Oxygen was delivered to patients in a rate of 4-6 $\mathrm{L} / \mathrm{min}$ through a nasal cannula. Intraoral spray of $10 \%$ lidocaine was applied just before the patient was positioned to left lateral decubitus position. A bolus of midazolam $2.5 \mathrm{mg}$ was administered IV. A target controlled infusion (TCI) pump (Injectomat ${ }^{\circledR}$ TIVA Agilia, Fresenius Kabi Ltd., UK) was used to target effect site concentration (Ce) of propofol within 1.2-2.0 $\mu \mathrm{g} / \mathrm{ml}$ and remifentanil within $1.0-2.5 \mathrm{ng} / \mathrm{ml}$ to achieve deep sedation. The target concentrations were adjusted to maintain deep sedation level throughout the ESD procedure at the discretion of anesthesiologist. The sedation management plan was as follows. If the patient seemed to show response or movement to a painful procedure, remifentanil Ce was increased by 0.1$0.2 \mathrm{ng} / \mathrm{ml}$, not exceeding maximum $2.5 \mathrm{ng} / \mathrm{kg}$. If the sedation depth needed to be deepened, $0.5 \mathrm{mg}$ midazolam was given
IV and if necessary propofol Ce was increased by $0.1 \mathrm{mg} / \mathrm{ml}$ subsequently, not exceeding a Ce of $2.0 \mathrm{mg} / \mathrm{ml}$. We intended to use a small amount of midazolam along with propofol to provide amnesia and reduce the amount of propofol needed. The patient's respiration was monitored with respiratory rate detected from the ECG and chest wall movement. We did not use a nasal cannula designed to simultaneously monitor end tidal carbon dioxide $\left(\mathrm{ETCO}_{2}\right)$ because it was not available at the ESD suite.

In this patient, ESD was difficult because of a large sized tumor $(2 \mathrm{~cm})$ and copious bleeding. At around 15-25 min after the start of ESD, the patient moved intermittently. At this point, the patient's respiratory pattern did not show obstructive type or apneic features, so we increased Ce of remifentanil first by $0.1-0.2 \mathrm{ng} / \mathrm{ml}$ and at subsequent intermittent movement, we administered midazolam $0.5 \mathrm{mg}$ IV three times at intervals. At around $35 \mathrm{~min}$, there were few episodes of brief desaturation to $\mathrm{SpO}_{2} \mathbf{8 8 \%}$, so the patient's chin was lifted for better oxygenation, and TCI drugs were adjusted to lower ranges to alleviate possible obstructive airways and apneic episodes from sedation. Despite efforts to secure airway by lifting the chin and jaw thrust with high flow of 8-10 ml/ min nasal oxygenation, $\mathrm{SpO}_{2}$ increased only briefly to $90 \%$ and finally dropped to $50 \%$. The endoscope was removed, and the patient was mask ventilated in lateral position with ambu-bagging under $100 \% \mathrm{O}_{2}$. Propofol and remifentanil drugs were all stopped. Manual mask ventilation was feasible in lateral position, but $\mathrm{SpO}_{2}$ remained below $80 \%$ with only a brief increase to $93 \%$. Therefore, we decided to intubate the patient, placed him to the supine position. By then it was detected that the patient's abdomen had been distended. After IV injecting $1 \mathrm{mg}$ midazolam and $50 \mathrm{mg}$ rocuronium $(0.77 \mathrm{mg} / \mathrm{kg})$ and mask ventilating for $2 \mathrm{~min}$, we performed tracheal intubation. At the same time, a paracentesis was performed by another physician using a $16 \mathrm{G}$ angiocath and the air leaked out from the abdomen, which meant pneumoperitoneum suspected to be from a gastric perforation. Mechanical ventilation was started, and $\mathrm{SpO}_{2}$ increased to $100 \%$. Ambu-bagging, tracheal intubation and paracentesis were all carried out briefly and simultaneously within 3-4 min. Hemodynamic profiles including blood pressure and heart rates were stable despite respiratory depression and desaturation throughout the event.

Upon request from the ESD endoscopist to awaken the pa- 
tient to assess for the hypoxic brain damage, we administered $200 \mathrm{mg}$ sugammadex IV ( $3 \mathrm{mg} / \mathrm{kg}$ ) because only $7 \mathrm{~min}$ had elapsed after rocuronium administration. The patient was able to obey commands within 3 min following sugammadex injection. After checking the patient's mental status, we decided to resume ESD under general anesthesia. Anesthesia was induced and maintained with propofol and remifentanil using TCI Ce of $2.5 \mu \mathrm{g} / \mathrm{ml}$ for propofol and $2.3 \mathrm{ng} / \mathrm{ml}$ for remifentanil. For neuromuscular blockade, $50 \mathrm{mg}$ rocuronium $(0.8 \mathrm{mg} / \mathrm{kg})$ was re-administered IV because of the 10 -min elapsed time from sugammadex administration. Mechanical ventilation was applied. ESD was restarted and endoscopic clipping was performed to repair the suspected perforation site of the stomach (Fig. 1). The remaining ESD took $50 \mathrm{~min}$. Upon completion of the ESD, propofol and remifentanil were discontinued and sugammadex $200 \mathrm{mg}$ was re-administered to reverse muscle relaxation. The patient was extubated after checking the complete emergence from anesthesia, and was transferred to the postanesthetic care unit (PACU). Train of four (TOF) monitoring was not available at the endoscopic suite. At the PACU, blood pressure was 122/70 $\mathrm{mmHg}$, pulse rate was 58 beats/min and respiratory rate was 14 breaths/ min. $\mathrm{SpO}_{2}$ was 96-97\% at room air. Abdominal distension was decreased. The patient was transferred to the general ward 70 min later. Chest radiograph at the PACU revealed pneumoperitoneum (Fig. 2A). Two days later, a follow-up EGD revealed no definite perforation site and the previous ESD lesion was covered with exudate. Follow-up chest radiograph on the fifth day showed remaining pneumoperitoneum but without clinical significance (Fig. 2B). The patient was discharged on the sixth day after ESD without specific complications.

\section{DISCUSSION}

We report a case of severe respiratory depression caused by gastric distention due to pneumoperitoneum from an unrecognized gastric perforation during ESD procedure. The incidence of gastric perforation during ESD is reported to range from $1.2-5.2 \%$, and gastric perforation is divided into macroperforation and microperforation [8]. In general, macroperforation is detected by endoscopists during ESD, and

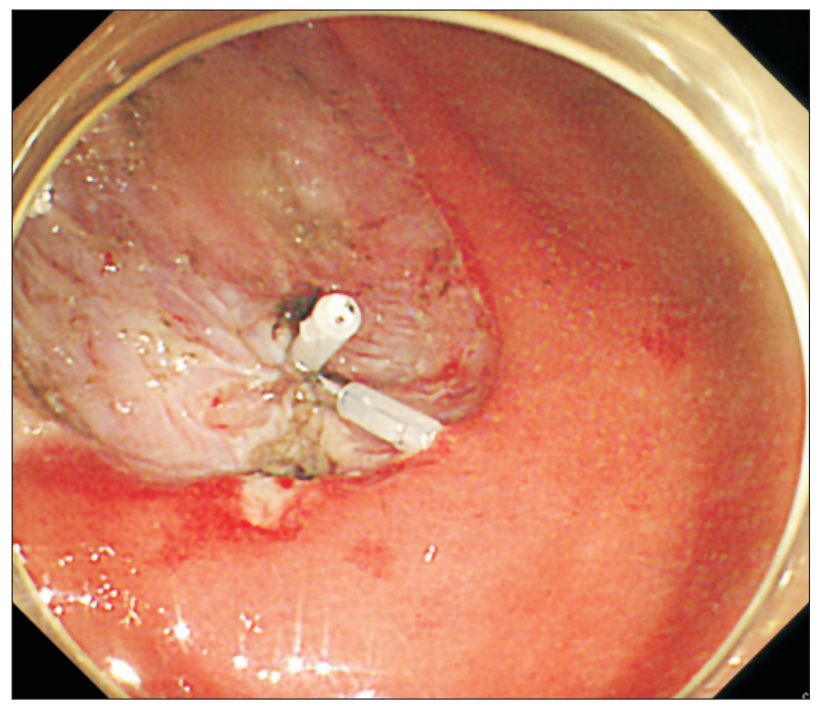

Fig. 1. Endogastroduodenoscopic view of a hemostatic clipping of the bleeder site in the submucosa of the stomach during endoscopic submucosal dissection procedure.

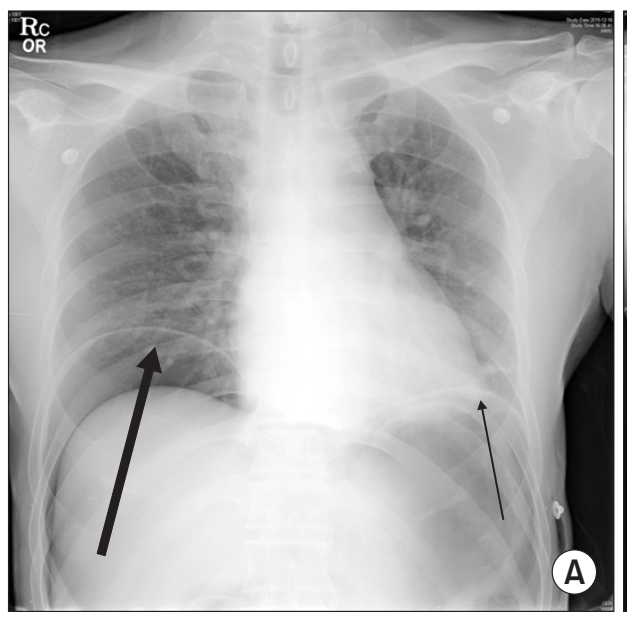

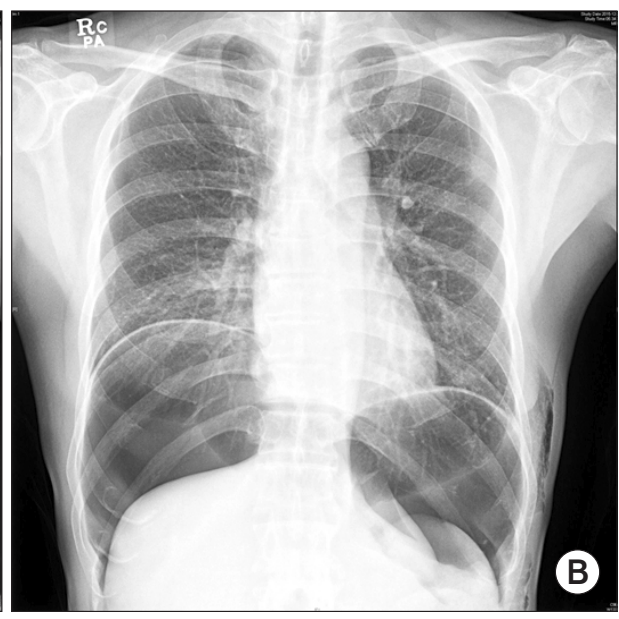

Fig. 2. Chest radiograph on the day of endoscopic submucosal dissection. Pneumoperitoneum is markedly increased compared to the preoperative chest radiograph. The arrows indicates free air (A). Chest radiograph on the postoperative 5 days delineates a remaining pneumoperitoneum and subcutaneous emphysema, but without clinical significance (B). 
can be treated by complete endoscopic closure with endoclips, and thereafter ESD can be continued. Microperforation is usually detected later after procedure by detecting free air in radiography and is treated conservatively. In Yoo et al. [8]' study, risk factors for all perforations include tumor location at the antrum or greater curvature, presence of fibrosis and long procedure time $>2 \mathrm{~h}$, and additional risk factors for microperforation include age $>81$ years and muscularis mucosal invasion. The symptoms and signs of gastric perforation include abdominal discomfort, change of vital signs, subcutaneous emphysema, and detection of pneumoperitoneum or pneumoretroperitoneum under fluoroscopy [9]. If abdominal fullness is severe because of air leakage from the perforated lesion, respiratory complications or neurogenic shock can ensue. Therefore, decompression of the pneumoperitoneum must be performed through paracentesis with a large-bore puncture needle [10]. In our case, the perforation could have been micro- because it was not readily detected by the endoscopist, or it could have been a macroperforation that has not been detected promptly because of the bleeding obscuring the perforated site. The latter seems more likely because our patient developed pneumoperitoneum that was severe enough to cause respiratory difficulty. Severe abdominal distension from pneumoperitoneum can cause elevation of the diaphragm, which restricts the lung volume, decreases venous return and cardiac output and may even leads to cardiopulmonary arrest depending on the degree of the intraabdominal pressure. The combination of acute abdominal distension with hemodynamic instability after endoscopic procedures should raise suspicion of tension pneumoperitoneum [11]. In our case, gastric perforation caused pneumoperitoneum, which resulted in severe respiratory depression, but it did not cause tension pneumoperitoneum. Gastric perforation during ESD should be suspected if the gastric lesion is large and seated at difficult location for the ESD procedure, if the procedure is prolonged with bleeding, if desaturation is not recovered despite the proper respiratory support or if the patient shows unusual movement during deep sedation. In these circumstances, gastric perforation needs to be ruled out. We have learned from this experience that in patients with risk factors for perforation and in difficult ESD cases, anesthesiologists and endoscopists should be aware of a possible perforation, intermittently palpate for abdominal distension and differentiate causes for respiratory difficulty.
Several studies have shown the safety and effectiveness of sedation, especially if sedative agents were administered continuously during ESD, and deep sedation precludes the need for general anesthesia $[4,5]$. In our institution, we practice deep sedation with intermittent bolus doses of midazolam and continuous infusion of propofol and remifentanil using a TCI pump, to help speed up the endoscopist's performance and for the comfort of the patient. Although we have not experienced any major complications, we are aware of potential sedation-related complications, such as respiratory depression, airway obstruction, pulmonary aspiration and aspiration pneumonia. These respiratory complications can be lethal if not recognized or managed properly early. Therefore, anesthesiologists should be in alert of the possibility of such a situation. The airway needs to be protected in a timely manner with chin lift and jaw thrust and nasal airway may be inserted during ESD. If severe respiratory depression ensues that is not managed with manual airway manipulation or mask ventilation, then antagonist drugs to opioid or midazolam, such as naloxone or flumazenil, could be considered, and insertion of laryngeal mask or intubation may be needed. Airway obstruction caused by laryngospasm or bronchospasm can cause hypoventilation and hypoxia, and so has to be rescued, as in an emergency respiratory resuscitation. The incidence of clinically recognized aspiration is low, and prevention to reduce aspiration chances, such as reducing fluids and secretion in the oral cavity, ensuring empty stomach and supplementing oxygen, may be needed. Postoperative encouragement to cough, confirming chest X-ray, administering antibiotics and applying physiotherapy may also be helpful [12]. Some clinicians prefer general anesthesia because it may block patient movement and reduce the risk of aspiration pneumonia [13]. In addition, general anesthesia may reduce the dissection time and enhance endoscopist's performance [2].

During this respiratory emergency situation, we had to intubate the patient, awaken the patient for neurologic assessment and reinstitute general anesthesia to proceed ESD in a short period of time. Reversal of deep or shallow neuromuscular blockade can be achieved by dose adjustment of sugammadex. Sugammadex $2 \mathrm{mg} / \mathrm{kg}$ is recommended for shallow block, which corresponds to the reappearance of second response in TOF or about $30 \mathrm{~min}$ after the administration of rocuronium $0.6 \mathrm{mg} / \mathrm{kg}$. Deep blockade represents 
no response to TOF stimulation with post-tetanic count of 1-2 responses, which is usually within 10-15 min of administration, and in this case sugammadex $4 \mathrm{mg} / \mathrm{kg}$ is required. According to Mirakhur, deep block was reversed within $3 \mathrm{~min}$ with sugammadex $4 \mathrm{mg} / \mathrm{kg}$ administration. For immediate reversal of rocuronium, larger doses of up to $16 \mathrm{mg} / \mathrm{kg}$ are required [14]. In our patient, sugammadex $3 \mathrm{mg} / \mathrm{kg}$ was given for reversal of rocuronium $0.77 \mathrm{mg} / \mathrm{kg} 7 \mathrm{~min}$ after rocuronium administration. The sugammadex dosing was less than recommended, but our intension to assess simple "obey to command" was capable with this amount, and immediately after neurologic assessment we induced general anesthesia within $10 \mathrm{~min}$ after sugammadex administration. According to Cammu et al. [15] a repeat dosing of rocuronium $0.6 \mathrm{mg} / \mathrm{kg}$ 5 min after reversal of neuromuscular block by sugammadex $4 \mathrm{mg} / \mathrm{kg}$ showed a mean onset time of rocuronium of 3.06 min and mean duration of block of $25.3 \mathrm{~min}$. In our patient, repeat dosing of rocuronium was $0.77 \mathrm{mg} / \mathrm{kg} 10 \mathrm{~min}$ after reversal of sugammadex $3 \mathrm{mg} / \mathrm{kg}$, and onset time was about $3 \mathrm{~min}$ and relaxation was clinically adequate for ESD. Reuse of rocuronium is possible after sugammadex reversal, but its duration of action may vary [15]. Therefore, we used sugammadex for final reversal at the end of the ESD procedure. In the literature, succinylcholine or benaylisoquinolone are considered reasonable drugs instead of rocurnoium in repeat dosing after sugammadex reversal [15], although this was not a consideration in this case.

One drawback in this case is lack of comprehensive monitoring devices for respiration. Although we monitored respiratory rate from the ECG, it is not accurate and does not provide information about the extent of respiration such as tidal volume. There are commercially available nasal cannulas that incorporate $\mathrm{ETCO}_{2}$ monitoring. In this case we did not use the oxygen nasal cannula that is designed to monitor simultaneous $\mathrm{ETCO}_{2}$ because it was not available at the ESD suite. Recently, the ExSpiron ${ }^{\mathrm{TM}}$ non-invasive respiratory monitoring device (Respiratory Motion, Inc., USA) has become available in the regional market. It would be useful in future cases to monitor minute ventilation in deeply sedated ESD patients.

In conclusion, when performing deep sedation for ESD, as in our case, one must suspect other causes of desaturation, such as gastric perforation, if desaturation does not recover despite proper respiratory support.

\section{REFERENCES}

1. Park YM, Cho E, Kang HY, Kim JM. The effectiveness and safety of endoscopic submucosal dissection compared with endoscopic mucosal resection for early gastric cancer: a systematic review and metaanalysis. Surg Endosc 2011; 25: 2666-77.

2. Yurtlu DA, Aslan F, Ayvat P, Isik Y, Karakus N, Ünsal B, et al. Propofol-based sedation versus general anesthesia for endoscopic submucosal dissection. Medicine (Baltimore) 2016; 95: e3680.

3. Park CH, Shin S, Lee SK, Lee H, Lee YC, Park JC, et al. Assessing the stability and safety of procedure during endoscopic submucosal dissection according to sedation methods: a randomized trial. PLoS One 2015; 10: e0120529.

4. Kiriyama S, Gotoda T, Sano H, Oda I, Nishimoto F, Hirashima $\mathrm{T}$, et al. Safe and effective sedation in endoscopic submucosal dissection for early gastric cancer: a randomized comparison between propofol continuous infusion and intermittent midazolam injection. J Gastroenterol 2010; 45: 831-7.

5. Park CH, Min JH, Yoo YC, Kim H, Joh DH, Jo JH, et al. Sedation methods can determine performance of endoscopic submucosal dissection in patients with gastric neoplasia. Surg Endosc 2013; 27: 2760-7.

6. Yoo YC, Park CH, Shin S, Park Y, Lee SK, Min KT. A comparison of sedation protocols for gastric endoscopic submucosal dissection: moderate sedation with analgesic supplementation vs analgesia targeted light sedation. Br J Anaesth 2015; 115: 84-8.

7. Sasaki T, Tanabe S, Azuma M, Sato A, Naruke A, Ishido K, et al. Propofol sedation with bispectral index monitoring is useful for endoscopic submucosal dissection: a randomized prospective phase II clinical trial. Endoscopy 2012; 44: 584-9.

8. Yoo JH, Shin SJ, Lee KM, Choi JM, Wi JO, Kim DH, et al. Risk factors for perforations associated with endoscopic submucosal dissection in gastric lesions: emphasis on perforation type. Surg Endosc 2012; 26: 2456-64.

9. Angsuwatcharakon P, Rerknimitr R. Endoscopic closure of iatrogenic perforation. Gastrointest Interv 2016; 5: 15-21.

10. Lee DW, Jeon SW. Management of complications during gastric endoscopic submucosal dissection. Diagn Ther Endosc 2012; 2012: 624835

11. Symeonidis N, Ballas K, Pavlidis E, Psarras K, Pavlidis T, Sakantamis A. Tension pneumoperitoneum: a rare complication of upper gastrointestinal endoscopy. JSLS 2012; 16: 495-7.

12. Amornyotin S. Sedation-related complications in gastrointestinal endoscopy. World J Gastrointest Endosc 2013; 5: 527-33.

13. Yamashita K, Shiwaku H, Ohmiya T, Shimaoka H, Okada H, Nakashima R, et al. Efficacy and safety of endoscopic submucosal dissection under general anesthesia. World J Gastrointest En- 
dosc 2016; 8: 466-71.

14. Mirakhur RK. Sugammadex in clinical practice. Anaesthesia 2009; 64 Suppl 1: 45-54.

15. Cammu G, de Kam PJ, De Graeve K, van den Heuvel M, Suy K,
Morias K, et al. Repeat dosing of rocuronium $1.2 \mathrm{mg} / \mathrm{kg}$ after reversal of neuromuscular block by sugammadex $4.0 \mathrm{mg} / \mathrm{kg}$ in anaesthetized healthy volunteers: a modelling-based pilot study. Br J Anaesth 2010; 105: 487-92. 